\title{
CINEMA DE AUTOR PARA PESSOAS COM DEFICIÊNCIA VISUAL: A AUDIODESCRIÇÃO DE O GRÃO
}

\section{AUTHOR'S CINEMA FOR THE VISUALLY IMPAIRED: THE AUDIODESCRIPTION OF O GRÃO(THE GRAIN)}

Vera Lúcia Santiago Araújo*

\section{RESUMO}

A audiodescrição (AD) é a tradução em palavras dos elementos visuais de uma produção audiovisual, tais como filmes, peças de teatro, jogos esportivos, obras de arte, dentre outros. A AD torna acessíveis essas produções audiovisuais a pessoas com deficiência visual. A pesquisa em $\mathrm{AD}$ de filmes vem se destacando dos demais tipos de $\mathrm{AD}$, envolvendo tanto estudos descritivos quanto exploratórios. Este trabalho tem o objetivo de apresentar os resultados de um desses estudos desenvolvidos pelo grupo de estudo LEAD (Legendagem e Audiodescrição) na Universidade Estadual do Ceará (UECE), no âmbito do projeto de cooperação entre a UECE e a UFMG (PROCAD). O estudo em questão abordou a recepção de pessoas com deficiência visual ao filme $O$ Grão, do cineasta cearense Petrus Cariry (2007). O filme fez parte de duas mostras de cinema acessível realizadas pelo LEAD, que cuidou do roteiro, gravação e edição. O LEAD também produziu O Grão em DVD, contendo menu com audionavegação, audiodescrição, legenda para surdos e janela de LIBRAS. A metodologia compreendeu uma dimensão descritiva, que classificou e analisou as inserções das descrições contidas no roteiro de $\mathrm{AD}$, e outra exploratória, que aplicou um teste de recepção sobre a AD do filme com dois grupos de pessoas com deficiência visual, sendo um grupo com cegueira congênita e total e o outro com baixa visão. Após assistir ao filme, o participante com deficiência visual fazia um relato livre sobre sua compreensão do enredo do filme. Por fim, respondia a um questionário versando sobre a opinião deles sobre a AD. Todo o processo era filmado para que também as reações ao filme pudessem fazer parte dos protocolos de análise. Foram consideradas duas variáveis: o espectador com deficiência visual e o gênero do filme. Os resultados mostraram que não houve diferença de recepção entre os dois grupos analisados, visto que os quatro participantes entenderam e apreciaram $\mathrm{O}$ Grão, considerado difícil para a maioria dos espectadores, pois foge à narrativa clássica do cinema de Hollywood. Os dados sugeriram que mesmo o cinema de autor pode

\footnotetext{
*. UECE, Fortaleza (CE), Brasil. verainnerlight@uol.com
} 
ser apreciado por uma audiência com deficiência visual por meio da AD.

Palavras chave: tradução audiovisual. audiodescrição. acessibilidade audiovisual.

\section{ABSTRACT}

Audiodescription (AD) is the translation into words of the visual elements of an audiovisual production, such as films, plays, sportive events, and paintings, among others. AD makes these audiovisual productions accessible to people with visual impairment. Research on $\mathrm{AD}$ has been focusing on films, involving both descriptive and exploratory studies. This paper aims to present the results of one of these studies developed by the research group LEAD (legendagem and audiodescrição) at the State University of Ceará (UECE) under the cooperation project between the Federal University of Minas Gerais (UFMG) and UECE (PROCAD). This study approached the reception of the visually impaired to the movie O Grão (The Grain) by the Brazilian filmmaker Petrus Cariri (2007). The film was part of two film festivals made accessible by LEAD, who handled its script, recording and editing. LEAD also produced The Grain on DVD with audionavigation menu, subtitling for the deaf, audiodescription and Sign Language interpreting. The methodology included a descriptive dimension, which classified and analyzed the description insertions contained in the AD script, and one exploratory, in which a reception test was applied with two groups of visually impaired participants. The first was formed by born blind subjects, and the second, low vision participants. After watching the film, the visually impaired participants made a free report about their understanding of the film plot. Then, they answered a questionnaire dealing with their opinion about the $\mathrm{AD}$. The whole process was filmed for the reactions to the film to be part of the analysis protocols. Two variables were considered: the type of visual impairment and the film genre. The results showed no difference in reception between the two groups analyzed, since the four participants understood and enjoyed The Grain, a film regarded as difficult by most viewers, because it is different from the typical classical narrative presented by Hollywood. The data suggested that even an author's film can be enjoyed by a visually impaired audience by means of AD.

Keywords: audiovisual translation; audiodescription; audiovisual accessibility.

\section{INTRODUÇÃO}

A audiodescrição (AD) é uma modalidade de tradução audiovisual (TAV) que se constitui em um recurso de acessibilidade desenvolvido para atender as necessidades de pessoas com deficiência visual. A AD de filmes consiste na descrição das informações que apreendemos visualmente e que não estão contidas nos diálogos, nem na trilha sonora, tornando-se assim acessível também para quem não enxerga. A AD pode ser chamada de tradução com base na definição de Jakobson (1995), que reconhece três tipos de tradução: a interlinguística (entre duas línguas 
diferentes), a intralinguística (dentro da mesma língua) e a intersemiótica (entre meios semióticos diferentes, do visual para o verbal e do verbal para o visual). A $\mathrm{AD}$, por se tratar da tradução de imagens em palavras, seria um exemplo do terceiro tipo apresentado pelo autor (JAKOBSON, 1995, p. 64-65).

A pesquisa em $\mathrm{AD}$, realizada pelo grupo de estudos $\mathrm{LEAD}$ (Legendagem e Audiodescrição) da Universidade Estadual do Ceará - UECE, pela Universidade Federal de Minas Gerais - UFMG e pelo grupo TRAMAD da Universidade Federal da Bahia - UFBA tem o objetivo de encontrar parâmetros de AD que atendam às necessidades das pessoas com deficiência visual no Brasil. Além disso, as três universidades também trabalham na formação de audiodescritores. Esta é a razão de o grupo da UECE estar desenvolvendo alguns trabalhos de AD em Fortaleza, como $\mathrm{AD}$ de filmes, peças de teatro e obras de arte. Um desses trabalhos foi a $\mathrm{AD}$ do filme O Grão.

O filme foi incluído em duas mostras de cinema e também foi alvo de um projeto de extensão chamado DVD Acessível, que produziu três DVDs com título do filme em Braille, menu com audionavegação e audiodescrição para pessoas com deficiência visual, bem como legenda e janela de LIBRAS para surdos.

Quanto às mostras, a primeira delas era intitulada Ouço Porque Vejo, Vejo Porque Ouço, primeira mostra de cinema para pessoas com deficiência visual e auditiva realizada no estado do Ceará. A primeira mostra aconteceu no Cine Benjamim Abrahão da Casa Amarela Eusélio Oliveira, equipamento cultural pertencente à Universidade Federal do Ceará -UFC, em agosto de 2009, como parte da programação do $19^{\circ}$ Cine Ceará - Festival Ibero Americano de Cinema. A segunda foi no Centro Cultural Banco do Nordeste, que recebeu a mostra em seu cine-teatro, como parte da programação do projeto intitulado Imagem em Movimento, mantido pelo Banco do Nordeste do Brasil (BNB). Durante a realização dessas exibições, mais de trezentas pessoas com deficiência visual e auditiva tiveram a oportunidade de assistir a vários curtas e longas-metragens nacionais em uma sala de cinema, muitos deles, inclusive, pela primeira vez na vida. Vale ressaltar que muitos dos filmes exibidos em festivais, em que o público normalmente é pequeno e diferenciado, visto ser formado, em sua maioria, por pessoas envolvidas de alguma forma com o chamado cinema de arte, terminam não entrando em circuito nacional.

Quando tivemos que audiodescrever o filme de Petrus Cariry - O Grão (2007) - enfrentamos muitas dificuldades em função de o filme ter uma estética bem diferente da que o público está acostumado. Ao invés da narrativa linear, na qual todos os elementos são encadeados em torno de um conflito cujas respostas serão dadas no final do filme, O Grão se desenrola lentamente com uma narrativa mais frouxa. Tem poucos diálogos, muitos planos fixos e tomadas contemplativas. 
O filme é composto de vários trechos longos, a maioria sem uma trilha sonora extra-diegética. Distancia-se, portanto, da narrativa clássica, típica do cinema de Hollywood. e se aproxima do que Vanoye e Goliot-Lété (1992:35) chamam de narrativa moderna ou do chamado cinema de autor.

Essa dificuldade pode ter acontecido também para as pessoas com deficiência visual. No entanto, durante as mostras acessíveis em que o filme foi exibido com $\mathrm{AD}$, essas pessoas não demonstraram dificuldades em acompanhar o filme até o final. Ao contrário, elas mostraram que tinham apreciado muito os filmes. No entanto, somente essa reação não nos dá certeza de que a $\mathrm{AD}$ possibilitou que o público com deficiência visual assistisse a filmes menos convencionais, como os estudos realizados por Franco em (2007) e Silva (2009), os quais mostraram que filmes com narrativas lineares, cujos enredos envolvem um conflito a ser resolvido no final, possuem uma boa recepção por parte de deficientes visuais. Nesse caso, o participante não teria que lidar com um excesso de descrições, já que as informações para o entendimento da trama ficavam divididas entre a trilha sonora do filme e a $\mathrm{AD}$. Este não é o caso de $\mathrm{O}$ Grão, cuja história é contada principalmente através de imagens. Para se ter uma idéia, os primeiros diálogos só ocorrem após dez minutos de filme, aumentando muito o número de inserções de AD. Precisávamos saber se esse gênero de filme poderia ser apreciado, por isso, decidimos realizar uma investigação mais rigorosa para podermos chegar a resultados mais conclusivos.

O objetivo deste artigo é apresentar os resultados dessa pesquisa descritivoexploratória que analisou a recepção à audiodescrição de $\mathrm{O}$ Grão. Para tanto, além desta introdução, o trabalho está dividido em mais cinco seções. Na segunda, abordam-se estudos sobre acessibilidade e audiodescrição no escopo da tradução audiovisual. Na terceira, são apresentados os procedimentos metodológicos da pesquisa. Na quarta, serão mostradas as etapas realizadas para a confecção do roteiro, gravação e edição da $\mathrm{AD}$ do filme. Na quinta, serão discutidos os resultados da pesquisa de recepção. Na última seção, considerações sobre o estudo são feitas e aponta-se para temas de futuras pesquisas.

\section{A PESQUISA EM AD}

Até onde se sabe, a modalidade de $\mathrm{AD}$ mais pesquisada é aquela usada em tradução de filmes e programas de TV. Neste sentido, podem-se citar os relatos de experiência de audiodescritores sobre sua prática profissional, tais como Benecke (2004), Snyder (2005) e Matamala (2007). No que diz respeito à pesquisa, os temas são mais diversificados. Temos o trabalho do grupo LEAD, do PROCAD 
(MAGALHÃES e ARAÚJO, no prelo), de Franco (2007) e de Silva (2009) no Brasil, e Casado (2007), Payá (2007) e Jimenez-Hurtado (2007), Jimenez-Hurtado et alli (2010) na Espanha.

A maioria dos trabalhos do LEAD e do PROCAD está em andamento. Estão sendo desenvolvidas dissertações de mestrado e trabalhos de conclusão de curso sobre a audiodescrição de filmes, peças de teatro e obras de arte. (MAGALHÃES E ARAÚJO, no prelo, e OLIVEIRA JÚNIOR, 2011)

Franco (2007, p. 171) demonstrou, por meio de pesquisa exploratória, que a presença do recurso facilitou a recepção de pessoas com deficiência visual a um filme de curta metragem. O filme Pênalti (Diretor: Adler Kibe Paz) foi exibido para vinte participantes, dez assistiram ao curta com $\mathrm{AD}$ e dez sem $\mathrm{AD}$. Os resultados indicaram que o primeiro grupo teve melhor desempenho nas respostas a um questionário sobre o conteúdo do curta, com $90 \%$ de acertos, contra $40 \%$ do segundo grupo.

Silva (2009) realizou uma pesquisa exploratória, enfocando a recepção de crianças a desenhos animados da Turma da Mônica com o intuito de delinear parâmetros para a elaboração de roteiros de $\mathrm{AD}$ de filmes infantis. Os resultados obtidos demonstraram que o uso da audiodescrição não só facilitou o entendimento dos desenhos, como tornou a experiência dos espectadores mais prazerosa e educativa. Os resultados sugeriram também a preferência das crianças por um estilo de narração com uma maior inflexão de voz, em oposição à narração mais monocórdia ou neutra, preconizada por alguns audiodescritores (SILVA, 2009). A participação do narrador, por meio de uma narração mais interpretativa, foi considerada fundamental pelas crianças.

Um grupo de pesquisadoras espanholas (JIMENEZ-HURTADO, CASADO e PAYÁ) analisou um corpus de mais 210 roteiros de filmes audiodescritos em espanhol, etiquetados para o desenvolvimento de três níveis de análise - narratológico, cinematográfico e gramatical (Jimenez Hurtado et alli, 2010). Cada uma delas examinou aspectos diferentes relacionados à AD. Payá (2007, p. 88-89) compara dois tipos de roteiro: o do filme e o da AD. A autora faz uma análise do filme Pulp Fiction de Quentin Tarantino (1994). Ela mostra que os dois roteiros são diferentes, porque ambos possuem objetivos distintos mesmo quando focalizam a mesma cena. Casado (2007, p. 137) aponta estratégias para caracterizar os personagens de uma AD. Segundo a autora, os personagens são descritos à medida que aparecem na tela. Ela frisa também que essa descrição deve ser feita ao longo do filme, já que, muitas vezes, os tempos sem fala a serem preenchidos com a $\mathrm{AD}$ são pequenos.

Jimenez-Hurtado et alli (2010, p. 71) propuseram parâmetros para a análise de roteiros de AD de filmes e programas de TV. Segundo a autora, a AD de filmes 
deve ter inserções, prioritariamente, entre as falas de uma produção audiovisual, observando a descrição de elementos visuais não verbais (personagens, ambientação, localização temporal e espacial e ações) e elementos visuais verbais (créditos iniciais e finais, disdascálias, legendas e letreiros).

Quadro 1: Parâmetros a serem usados numa audiodescrição, segundo Jiménez Hurtado $(2010$, p.71)

\section{ELEMENTOS VISUAIS NÃO VERBAIS}

\section{Personagens}

1.1. Apresentação

1.2. Identificação do ator ou atriz que interpreta o personagem

1.3. Atributos físicos (idade, etnia, aspecto, vestuário, expressões faciais, linguagem corporal)

1.4. Estados

1.4.1. Estados emocionais

Positivos (alegria, ânimo serenidade ternura)

Negativos (Tristeza, Desânimo, Desesperança, Ira, Medo)

1.4.2. Estados físicos

1.4.3. Estados mentais

2. Ambientação

2.1. Localização

Espacial (interiores e exteriores)

Temporal

2.2. Descrição (interiores e exteriores)

3. Ações

\section{ELEMENTOS VISUAIS VERBAIS}

1. Créditos

2. Inserções (textos, títulos, legendas, intertítulos)

Por meio dos resultados da análise textual do corpus usando o Wordsmith Tools, a autora derrubou dois mitos dentro da prática da audiodescrição. O primeiro foi o do uso das palavras "olhe" e "veja" (JIMENEZ-HURTADO, 2007, p.74), consideradas politicamente incorretas em muitas diretrizes de AD. Ao procurar pelas palavras mais frequentes, deparou-se justamente com essas duas. Depois das preposições e dos artigos, elas foram as mais utilizadas pelos audiodescritores. $\mathrm{O}$ segundo mito derrubado foi o de que não se deve colocar sua interpretação na AD (HOLLAND, 2009, p. 192). A estrutura oracional que mais aparece (30\% dos casos) é SUJEITO - PREDICADO - PREDICATIVO: ALGUÉM SORRI EMOCIONADO. O predicativo nesse tipo de construção implica em interpretação. A descrição é feita a partir de uma visão subjetiva (emocionado) da representação oferecida pelo verbo principal (sorri) (JIMENEZ-HURTADO, 2007, p. 77). 


\section{PROCEDIMENTOS METODOLÓGICOS}

O estudo envolveu duas dimensões: uma descritiva, que analisa o roteiro de O Grão, segundo os parâmetros preconizados por Jimenez Hurtado (2007) e a outra exploratória, que testou a $\mathrm{AD}$ com dois grupos de participantes com deficiência visual, verificando como essa modalidade de tradução foi recebida por elas. As duas dimensões são pautadas por análises qualitativas.

A etapa descritiva foi feita manualmente, elaborando-se três tabelas com a ajuda do editor de textos Microsoft Word para agrupar as inserções de acordo com os parâmetros. A análise prescindiu de etiquetação para análise automatizada, porque O Grão é relativamente curto com apenas oitenta e oito minutos de duração. A quantidade de inserções elaboradas para o roteiro de $\mathrm{AD}$ do filme, um total de duzentas e noventa e oito, incluindo-se os créditos, não justificava buscar auxílio de algum desses programas. A análise compreendeu o estudo quali-quantitativo das inserções necessárias para audiodescrever as imagens do filme.

O processo de classificação auxiliou a examinar quantas inserções foram necessárias para descrever as imagens registradas pela câmera de Petrus Cariry. Depois, essas inserções foram analisadas uma a uma para vermos como essas imagens foram descritas. Por fim, foram estudados os parâmetros utilizados para descrever os personagens, a ambientação e as ações. A preparação do corpus foi finalizada com a classificação dos elementos visuais não verbais, como os créditos, os letreiros e as legendas.

A etapa exploratória consistiu na avaliação da recepção de quatro participantes ao filme, dos quais dois com deficiência visual total de nascença e dois com baixa visão. Foram consideradas duas variáveis, o tipo de deficiência e o gênero do filme. No que diz respeito à primeira variável, buscou-se verificar se haveria diferenças na recepção do filme pelos dois grupos, porque se esperava que os cegos de nascença tivessem mais dificuldades por conta da falta de referências visuais estocadas na memória. Quanto à segunda, pretendeu-se verificar se um filme de autor, lento, com ações contidas, poucos diálogos, personagens não-glamorosos poderia ser apreciado por pessoas com deficiência visual por meio de uma AD roteirizada segundo os parâmetros de Jimenez-Hurtado (2007).

O Grão é obra mais relevante até o presente momento dirigida pelo cineasta Petrus Cariry. Foi premiada nacional e internacionalmente. Suas características marcantes são a bela fotografia, a construção da narrativa conduzida pelas imagens e a contenção das falas e de trilha sonora adicionada. O que se ouve em quase todo o desenrolar da trama são os sons diegéticos: o chocalho dos bodes, a máquina de tear, o som da TV etc. O filme conta história de Perpétua, uma velha senhora que, 
sentindo a morte iminente, resolve preparar seu neto Zeca para a separação que se aproxima, contando-lhe a história de um rei e uma rainha muito ricos e poderosos, que perderam o único filho e querem trazê-lo de volta à vida por meio da descoberta do grão da vida. A história se passa no sertão nordestino, onde Damião e Josefa, pais de Zeca, sobrevivem com dificuldades, trabalhando duro para sustentar a família.

A coleta de dados foi feita individualmente, ou seja, cada participante assistiu ao filme sozinho, para que um deficiente visual não influenciasse o outro. Antes de assistir ao filme, o participante assinou um termo de consentimento livre e esclarecido e preencheu um questionário pré-coleta, para que soubéssemos o perfil de cada um. Após assistir ao filme, o participante com deficiência visual fez um relato livre sobre sua compreensão do enredo do filme. Por fim, respondeu a um questionário versando sobre a opinião deles sobre a $\mathrm{AD}$. Todo o processo foi filmado para que também as reações ao filme pudessem fazer parte dos protocolos de análise. Resumindo, os documentos a serem analisados para a verificação das hipóteses são: reações dos participantes ao assistirem ao filme, relato retrospectivo e questionário pós-coleta.

\section{A AD DE O GRÃO: ROTEIRIZAÇÃO, GRAVAÇÃO E EDIÇÃO 3.1. A Elaboração da AD}

A elaboração da $\mathrm{AD}$ foi realizada em cinco etapas organizadas na ordem que segue: análise das imagens, identificando-se os espaços para as inserções e definindo-se a priorização do que seria descrito; elaboração do roteiro com o auxílio do software Subtitle Workshop (SW), avaliado posteriormente por um consultor com deficiência visual, produção do roteiro com todas as rubricas e orientações necessárias para a locução; gravação do áudio e, finalmente, edição e mixagem da $\mathrm{AD}$ e do som original do filme.

$\mathrm{Na}$ elaboração do roteiro, utilizou-se o SW, que é um dos softwares de legendagem mais simples e comumente utilizados, na versão 2.51 , desenvolvido pela URUsoft. Apesar de ser um programa de legendagem, seu uso nos permite marcar o início e o fim de cada inserção enquanto vemos o filme, que pode ser acessado no software. Um arquivo com as marcações de início e fim de cada inserção, gerado no SW, permite-nos elaborar o roteiro para ser gravado. Esses dados são transferidos para o processador de textos Word. A Figura 1 mostra esse arquivo, contendo o número de ordem da linha de texto (1) da $\mathrm{AD}$, o tempo de entrada e de saída - TCR (2) e o texto (3). 
Figura 1: Arquivo com extensão *srt aberto com Bloco de Notas

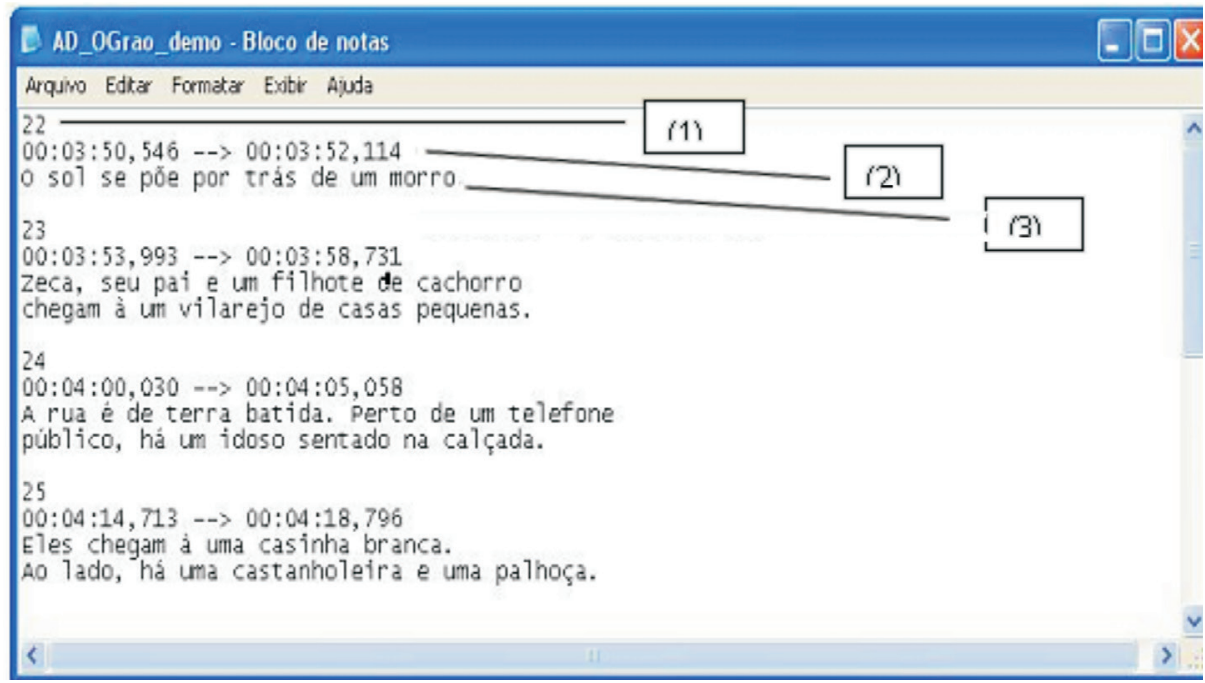

Em seguida, organizamos o roteiro em uma tabela, contendo os seguintes elementos: número sequencial das descrições; tempo inicial e final, conhecidos tecnicamente como TCR (Time Code Reader), o qual se refere ao intervalo de tempo

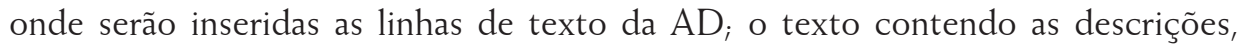
elaboradas a partir do estudo das imagens; as deixas, que são as últimas falas antes de entrar a $\mathrm{AD}$, e as rubricas, que são as instruções para a locução (falar rápido, falar muito rápido, etc.). Uma amostra desse roteiro é mostrada na Figura 2.

Figura 2: Trecho do roteiro de AD de $O$ Grão

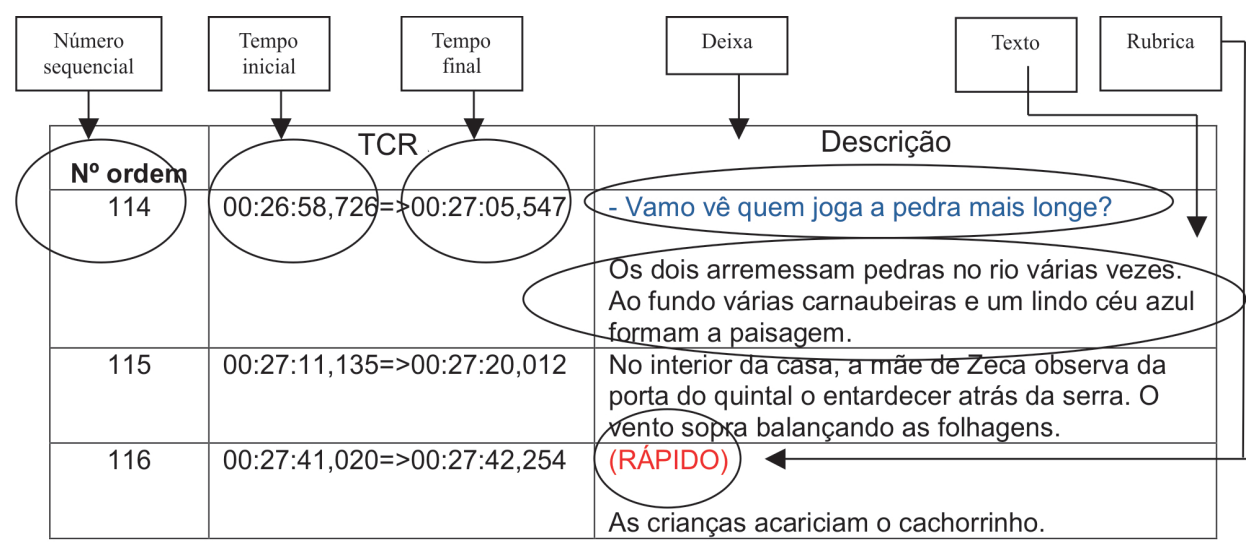


Antes de ser gravado, o roteiro é avaliado por um consultor com deficiência visual, a fim de revisar o texto, examinar o ritmo da narração e o sincronismo das imagens com as descrições de forma que as mesmas não se sobreponham aos diálogos. A gravação é feita com auxílio de um computador, um microfone profissional, uma mesa de som, um fone de ouvido e um software de edição de áudio e vídeo. A $\mathrm{AD}$ termina com a edição e mixagem do som da $\mathrm{AD}$ e da a trilha sonora do filme. Utilizando um programa de edição de som, a faixa da AD é editada, eliminandose os ruídos, equalizando-se a voz gravada (grave, médio, agudo), e ajustando-se o volume, a fim de torná-lo inteligível e o mais agradável possível aos ouvidos da audiência. Em seguida, utilizando um programa de edição de vídeo, a AD é incorporada ao filme, encaixando-se as inserções no tempo exato e equalizando-se as duas trilhas sonoras, de forma que ambas alcancem os mesmos níveis de áudio.

\subsection{Análise do Roteiro}

\subsubsection{Descrição dos personagens}

Trinta e seis inserções foram usadas para descrever os personagens. A família mostrada no filme (Zeca, Fátima, Perpétua, Josefa e Damião) é retratada pelos olhares, pelo silêncio e por uma série de gestos minimalistas que nos dizem muito mais deles do que os diálogos. Todos os personagens gravitam em torno de Zeca. Com exceção de sua irmã Fátima, nomeada no início da trama, todos os outros personagens são apresentados pelo seu parentesco com o menino: Perpétua, a avó, Josefa, a mãe ; e Damião, o pai. A decisão do diretor de não revelar o nome dos personagens secundários na primeira metade da trama resulta num filme que não revela somente o cotidiano da família de Zeca, mas também parece uma alusão ao estilo de vida das famílias sertanejas. Assim, o roteiro da AD preservou essa característica e seguiu a mesma linha de trabalho de Petrus.

O número de trinta e seis inserções pode parecer pequeno ao ser comparado com as demais, porém, se levarmos em consideração os relatos dos participantes durante a pesquisa exploratória, verificaremos que foram suficientes para que o espectador tivesse uma visão geral sobre cada personagem e identificasse cada um deles, sem que nenhum passasse despercebido.

Os personagens não foram descritos de uma vez só, como num conto ou romance. Seu perfil vai sendo traçado ao longo do filme (CASADO, 2007). Aos poucos, o expectador vai ouvindo pequenos detalhes singulares de cada um deles, tais como o modo de vestir, a reação diante de uma determinada situação, algumas características físicas etc. Vale ressaltar, ainda, que a construção da imagem dos 
personagens por parte dos participantes se faz por meio de um misto de informações contidas no roteiro e nos diálogos.

Vejamos agora a descrição do personagem principal. Sem uma compreensão total de Zeca, seria impossível apreciar a trama, já que quase todo o filme se passa segundo o seu ponto de vista.

\section{Quadro 2: Descrição do personagem Zeca}

\begin{tabular}{|c|lc|l|}
\hline No ordem & \multicolumn{1}{|c|}{ TCR } & \multicolumn{1}{|c|}{ Descrição } \\
\hline 18 & $\begin{array}{l}00: 02: 49,707 \\
00: 02: 56,228\end{array} \quad=>$ & $\begin{array}{l}\text { Um menino moreno de cabelos curtos, sem camisa e com água na } \\
\text { cintura segura uma vara. }\end{array}$ \\
\hline 79 & $\begin{array}{c}00: 18: 10,098 \\
00: 18: 20,417\end{array} \quad=>$ & $\begin{array}{l}\text { Na estrada, Zeca, de perfil, caminha com a caixa em uma das mãos } \\
\text { e o cachorrinho na outra. Usa camisa marrom de mangas curtas. A } \\
\text { vegetação é seca e cinzenta. }\end{array}$ \\
\hline 222 & $\begin{array}{c}01: 02: 56,405 \\
01: 03: 04,836\end{array} \quad=>$ & $\begin{array}{l}\text { As mãos de Zeca cortando uma folha seca preenchem a tela. Ele usa } \\
\text { calção verde e está sem camisa. Seus braços estão sujos. }\end{array}$ \\
\hline 223 & $\begin{array}{l}01: 03: 28,594 \\
01: 03: 35,397\end{array} \quad=>$ & Lentamente seu rosto é mostrado. Ele tem cabelos e olhos pretos. \\
\hline 259 & $\begin{array}{l}01: 16: 58,499 \\
01: 17: 08,118\end{array} \quad=>$ & $\begin{array}{l}\text { As crianças estão sentadas em cadeiras de madeira. Zeca usa um } \\
\text { chapéu verde. A professora volta e distribui ovos coloridos. }\end{array}$ \\
\hline
\end{tabular}

Pelas inserções, pode-se ter uma ideia da situação de pobreza em que vive o menino, já que ele aparece quase sempre sem camisa, com a mesma roupa ou sujo de terra. Também o ambiente em que vive colabora para a sua caracterização, pois mostra as condições precárias de subsistência que aquele lugar tão longínquo oferece. Podemos perceber isto na inserção 79 do Quadro 2 e na seguinte descrição: "Zeca e seu pai caminham pela estrada de terra batida." (inserção número 206, 00:53:42,445 => 00:53:48,378).

Pelo relato retrospectivo de um dos participantes com deficiência visual, percebemos que a importância de Zeca na trama foi observada. Vimos também que o participante estava harmonizando descrição e diálogos, quando disse o nome do cachorro de Zeca, o qual só é nomeado na metade do filme, numa cena em que ele e uma menina discutem o nome do cachorro $(\mathrm{Mu})$ :

(...) realmente importou porque quando tá passando uma cena que o Zeca era o centro, o foco da cena, então a gente se orienta pela audiodescrição, com certeza, se não fosse isso, se tivesse o Mu lá dormindo do lado da cama, eu jamais iria saber que era o Zeca que tava dormindo lá. 
Depois de Zeca, a outra personagem importante na trama era sua avó Perpétua. A morte próxima, a saúde frágil, a forte ligação com o neto e a preparação do menino para aceitar este fato são os fios condutores da narrativa, como mostra o Quadro 3:

Quadro 3: Descrição do personagem Perpétua (a avó de Zeca)

\begin{tabular}{|c|lc|l|}
\hline$N^{\circ}$ ordem & \multicolumn{1}{|c|}{ TCR } & \multicolumn{1}{|c|}{ Descrição } \\
\hline 28 & $\begin{array}{l}00: 04: 24,500 \\
00: 04: 29,480\end{array} \quad=>$ & $\begin{array}{l}\text { Uma idosa sentada de costas em um banco de madeira observa } \\
\text { Zeca à sua frente. }\end{array}$ \\
\hline 48 & $\begin{array}{l}00: 07: 47,092 \\
00: 07: 58,899\end{array} \quad=>$ & $\begin{array}{l}\text { A idosa caminha com uma bengala pela sala da TV. Lentamente, } \\
\text { passa pela cozinha. Sai de cena. }\end{array}$ \\
\hline 51 & $\begin{array}{l}00: 08: 55,904 \\
00: 09: 03,514\end{array} \quad=>$ & $\begin{array}{l}\text { No quarto, a idosa está de costas ao lado de Zeca. Usa um lenço } \\
\text { velho na cabeça. À sua frente, um baú de madeira e um banco de } \\
\text { couro. }\end{array}$ \\
\hline 252 & $01: 13: 48,631$ \\
$01: 13: 54,911$ & $=>$ & No quarto, sob o véu, a avó continua deitada imóvel. \\
\hline
\end{tabular}

A relação de amor entre avó e neto foi percebida também por outro participante, demonstrando que a $\mathrm{AD}$ possibilitou essa compreensão, já que a cena mencionada só aparece visualmente:

O filme também mostra um menino, ele é muito apegado à avó e ele também ajuda em casa... ele é tão apegado à avó que a gente vê que ele consegue... ele pega uma maçã que cai... das várias maçãs ele pega uma sem que a pessoa que derrubou as maçãs veja e ele traz... e ao invés de ele comer a maçã sozinho ou compartilhar com as outras pessoas da casa, ele vai dividir essa maçã junto com essa avó dele, que conta muitas histórias.

Os pais de Zeca são retratados como sertanejos sofridos e endurecidos pelas dificuldades de sobrevivência. 
Quadro 4: Descrição dos personagens Josefa e Damião (os pais de Zeca)

\begin{tabular}{|c|c|c|c|}
\hline $\mathrm{N}^{\circ}$ ordem & TCR & & Descrição \\
\hline 19 & $\begin{array}{l}00: 02: 56,300 \\
00: 03: 01,328\end{array}$ & $=>$ & $\begin{array}{l}\text { Ao fundo, na estrada, um homem de chapéu de couro tange } \\
\text { bodes. }\end{array}$ \\
\hline 31 & $\begin{array}{l}00: 04: 43,019 \\
00: 04: 46,495\end{array}$ & $=>$ & Uma mulher magra de cabelos curtos manuseia um tear. \\
\hline 221 & $\begin{array}{l}01: 00: 47,359 \\
01: 00: 53,772\end{array}$ & $\Rightarrow$ & $\begin{array}{l}\text { Na sala, o pai está deitado na rede. } 0 \text { semblante aparenta } \\
\text { cansaço e tristeza. }\end{array}$ \\
\hline 238 & $\begin{array}{l}01: 09: 54,692 \\
01: 10: 00,677\end{array}$ & $\Rightarrow>$ & $\begin{array}{l}\text { Josefa se aproxima e observa D. Perpétua. Seu rosto triste } \\
\text { preenche a tela. }\end{array}$ \\
\hline 266 & $\begin{array}{l}01: 19: 27,467 \\
01: 19: 33,624\end{array}$ & $\Rightarrow>$ & $\begin{array}{l}\text { Josefa com os braços cruzados está parada fora da casa. Seu } \\
\text { rosto sofrido preenche a tela. }\end{array}$ \\
\hline 283 & $\begin{array}{l}01: 23: 57,838 \\
01: 24: 02,622\end{array}$ & $\Rightarrow>$ & $\begin{array}{l}\text { No outro cômodo com a mãe, Fátima experimenta o vestido de } \\
\text { noiva. Josefa sorri. }\end{array}$ \\
\hline
\end{tabular}

Ao contrário da avó e dos pais de Zeca, sua irmã está sempre alegre e sorridente. Como Zeca, ela parece viver feliz apesar da vida difícil que leva. Seus pensamentos estão todos voltados para o seu casamento próximo com Josué. Fátima parece representar um contraponto entre o sofrimento da vida no sertão e a espera de dias melhores.

\section{Quadro 5: Descrição da personagem Fátima}

\begin{tabular}{|c|c|c|c|}
\hline $\mathrm{N}^{\circ}$ ordem & \multicolumn{2}{|c|}{ TCR } & Descrição \\
\hline 32 & $\begin{array}{l}00: 04: 50,357 \\
00: 04: 54,760\end{array}$ & $=>$ & $\begin{array}{l}\text { Uma moça usando fones de ouvido manuseia tiras de pano em } \\
\text { uma bacia. }\end{array}$ \\
\hline 40 & $\begin{array}{l}00: 06: 23,529 \\
00: 06: 33,466\end{array}$ & $=>$ & $\begin{array}{l}\text { A moça se levanta e retira as mãos da bacia. Enxuga as mãos no } \\
\text { vestido de cor vermelha com listras brancas na altura do busto. } \\
\text { Apanha uns cordões azuis que estão pendurados na cerca. }\end{array}$ \\
\hline 46 & $\begin{array}{l}00: 07: 20,070 \\
00: 07: 28,649\end{array}$ & $\Rightarrow>$ & $\begin{array}{l}\text { Sua irmã leva os talheres para a mesa. Está de short e blusa } \\
\text { brancos. Continua com os fones de ouvido. Volta para o cômodo } \\
\text { anterior, dançando. }\end{array}$ \\
\hline 95 & $\begin{array}{l}00: 23: 29,883 \\
00: 23: 40,939\end{array}$ & $\Rightarrow$ & $\begin{array}{l}\text { Na casa, Fátima toma banho com a porta entreaberta. Tem pele } \\
\text { branca e seios médios. Joga água pelo corpo com uma panela } \\
\text { de alumínio. }\end{array}$ \\
\hline 104 & $\begin{array}{l}00: 24: 56,217 \\
00: 25: 04,014\end{array}$ & $=>$ & $\begin{array}{l}\text { Fátima entra numa oficina. Está de short vermelho, blusa amarela } \\
\text { e sandálias. Na calçada, há três bicicletas. }\end{array}$ \\
\hline 112 & $\begin{array}{l}00: 26: 07,649 \\
00: 26: 16,601\end{array}$ & $=>$ & $\begin{array}{l}\text { Na estrada, passam por uma vegetação seca. Fátima abraça o } \\
\text { rapaz. Com a cabeça em seu ombro, ela tem um olhar sonhador. }\end{array}$ \\
\hline 162 & $\begin{array}{l}00: 40: 49,631 \\
00: 40: 52,954\end{array}$ & $\Rightarrow$ & Ela está com fones de ouvido. Borda num bastidor. \\
\hline
\end{tabular}




\begin{tabular}{|c|lr|l|}
\hline 172 & $\begin{array}{l}00: 43: 05,028 \\
00: 43: 08,591\end{array}$ & $=>$ & Ela está usando o vestido vermelho. \\
\hline 257 & $\begin{array}{l}01: 15: 39,501 \\
01: 15: 49,961\end{array}$ & $=>$ & $\begin{array}{l}\text { Na casa, Fátima lixa as unhas encostada à janela. Ao seu lado, há } \\
\text { uma bacia com retalhos. No armador, há uma bolsa e uma rede. } \\
\text { Fátima usa o vestido vermelho e fones de ouvido. }\end{array}$ \\
\hline 283 & $\begin{array}{l}01: 23: 57,838 \\
01: 24: 02,622\end{array}$ & $=>$ & $\begin{array}{l}\text { No outro cômodo com a mãe, Fátima experimenta o vestido de } \\
\text { noiva. Josefa sorri. }\end{array}$ \\
\hline 284 & $01: 24: 05,405$ & $=>$ & Fátima se olha no espelho e sorri. \\
\hline
\end{tabular}

Do mesmo jeito que aconteceu com Zeca, a dureza do ambiente também aparece influenciando os personagens, até mesmo a alegre Fátima, como mostra a inserção 112 do Quadro 5.

\subsubsection{Descrição da ambientação}

O sertão foi, muito mais do que Zeca e sua família, o foco das atenções do diretor, pois foi a ambientação o parâmetro que obteve a maioria das inserções, um total de cento e quarenta e nove. A câmera de Petrus Cariry mostrou incessantemente a paisagem seca e árida do nordeste e o interior e o exterior da casa onde mora a família. O Quadro 6 traz as algumas das inserções que caracterizam a paisagem nordestina:

Quadro 6: Descrição da paisagem nordestina

\begin{tabular}{|c|ll|l|}
\hline$N^{0}$ ordem & \multicolumn{1}{|c|}{ TCR } & \multicolumn{1}{|c|}{ Descrição } \\
\hline 7 & $\begin{array}{l}00: 00: 46,613 \\
00: 00: 51,651\end{array} \quad=>$ & $\begin{array}{l}\text { Uma rodovia de mão dupla que corta o sertão é vista de dentro } \\
\text { de um veículo em movimento. }\end{array}$ \\
\hline 8 & $\begin{array}{l}00: 00: 52,826 \\
00: 00: 55,948\end{array} \quad=>$ & Às margens da rodovia uma vegetação seca. \\
\hline 68 & $\begin{array}{l}00: 15: 50,981 \\
00: 16: 02,377\end{array} \quad=>$ & $\begin{array}{l}\text { Lentamente a câmera percorre o quintal, onde há uma pequena } \\
\text { planta de folhas finas e verdes, um bode, chão seco, uma cerca de } \\
\text { pau-a-pique e uma árvore com poucas folhagens. }\end{array}$ \\
\hline 231 & $01: 05: 23,185$ \\
$01: 05: 36,052$ & $=>$ & $\begin{array}{l}\text { Sertão. A paisagem é seca e há duas árvores ao fundo. Atrás } \\
\text { delas há uma cerca de pau-a-pique. Bodes caminham perto das } \\
\text { árvores. Ao longe, o pai tange os animais. }\end{array}$ \\
\hline
\end{tabular}

A casa revela a intimidade dos personagens no seu convívio familiar e quase se constitui em mais um personagem à medida que o espectador mergulha naquele universo particular do cotidiano da família, conhece seus móveis, utensílios e eletrodomésticos (Quadro 7). 
Quadro 7: Descrição da casa de Zeca

\begin{tabular}{|c|c|c|}
\hline $\mathrm{N}^{0}$ ordem & TCR & Descrição \\
\hline 25 & $\begin{array}{l}00: 04: 14,713=> \\
00: 04: 18,796\end{array}$ & $\begin{array}{l}\text { Eles chegam a uma casinha branca. Ao lado, há uma castanholeira } \\
\text { e uma palhoça. }\end{array}$ \\
\hline 43 & $\begin{array}{l}00: 07: 07,637=> \\
00: 07: 11,837\end{array}$ & $\begin{array}{l}\text { Noite. Imagem de três cômodos da casa. A irmã de Zeca está na } \\
\text { cozinha no canto esquerdo do vídeo. }\end{array}$ \\
\hline 44 & $\begin{array}{l}00: 07: 11,991=> \\
00: 07: 15,323\end{array}$ & O pai, à direita, assiste à TV em outro cômodo \\
\hline 48 & $\begin{array}{l}00: 07: 47,092=> \\
00: 07: 58,899\end{array}$ & $\begin{array}{l}\text { A idosa caminha com uma bengala pela sala da TV. Lentamente, } \\
\text { passa pela cozinha. Sai de cena. }\end{array}$ \\
\hline 51 & $\begin{array}{l}00: 08: 55,904=> \\
00: 09: 03,514\end{array}$ & $\begin{array}{l}\text { No quarto, a idosa está de costas ao lado de Zeca. Usa um lenço } \\
\text { velho na cabeça. À sua frente, um baú de madeira e um banco } \\
\text { de couro. }\end{array}$ \\
\hline 56 & $\begin{array}{l}00: 09: 51,026=> \\
00: 09: 59,022\end{array}$ & $\begin{array}{l}\text { Na mesa há uma caneca de alumínio sobre um pote, uma bacia, } \\
\text { um prato vermelho, dois pratos brancos, uma garrafa de cachaça } \\
\text { e outra caneca. }\end{array}$ \\
\hline 63 & $\begin{array}{l}00: 14: 37,253=> \\
00: 14: 49,241\end{array}$ & $\begin{array}{l}\text { Volta e apanha uma cesta que está ao lado da mãe. Senta-se } \\
\text { em um banco de alvenaria. Na parede suja, atrás do pai, há uma } \\
\text { imagem de Jesus. }\end{array}$ \\
\hline 64 & $\begin{array}{l}00: 14: 54,738=> \\
00: 15: 04,197\end{array}$ & $\begin{array}{l}\text { No quarto, a avó cobre Zeca com um mosqueteiro. Sobre o criado } \\
\text { mudo há uma caneca de alumínio e uma lamparina acesa. }\end{array}$ \\
\hline 66 & $\begin{array}{l}00: 15: 39,282=> \\
00: 15: 42,822\end{array}$ & $\begin{array}{l}\text { Dia. Uma porta se abre para o quintal. As paredes são velhas e } \\
\text { descascadas. }\end{array}$ \\
\hline 225 & $\begin{array}{l}01: 04: 08,084=> \\
01: 04: 18,643\end{array}$ & $\begin{array}{l}\text { Do interior do quarto, é mostrada a sala com a mesa, três cadeiras } \\
\text { e um banquinho, todos de madeira. Sobre a mesa está o pote com } \\
\text { um copo de alumínio emborcado no gargalo. }\end{array}$ \\
\hline 226 & $\begin{array}{l}01: 04: 21,866=> \\
01: 04: 32,094\end{array}$ & $\begin{array}{l}\text { Agora é mostrada a mesa da cozinha. Sobre ela há uma panela } \\
\text { preta, uma garrafa térmica, uma tábua de carne, garrafas } \\
\text { plásticas, a garrafa de bebida e pratos. }\end{array}$ \\
\hline 227 & $\begin{array}{l}01: 04: 32,756=> \\
01: 04: 41,444\end{array}$ & $\begin{array}{l}\text { Ainda na cozinha é mostrado o pote grande com um pano e uma } \\
\text { caneca de alumínio em seu gargalo. A luz do sol entra pela porta } \\
\text { aberta e ilumina o ambiente. }\end{array}$ \\
\hline
\end{tabular}

O fato de haver muitas descrições da casa pode ter sido a intenção do cineasta de transmitir ao seu espectador a luta diária daquela família para sobreviver no sertão. A câmera parece estabelecer uma relação de intimidade entre a família e o espectador, já que pode acompanhar cada movimento de todos os componentes da família, como se fosse mais um membro dela, vivendo no mesmo ambiente, na mesma casa, passando pelas mesmas dificuldades e vivenciando cada sofrimento. 
Portanto, uma $\mathrm{AD}$ que não contemplasse esse elemento, muito provavelmente, poderia comprometer a audiência do espectador com deficiência visual na maioria das cenas, privando-o destas informações visuais relevantes para a compreensão do filme e envolvimento com a trama.

Todo o cuidado nas descrições chamou a atenção dos participantes com deficiência visual, já que um deles colocou a relevância da descrição da ambientação:

Acho que é importante porque norteia você a imaginar uma coisa. A hora que ele falou ali, descrevendo a casa, pelo que você percebeu, o tipo do quarto dava pra você ver a sala... foi o que me passou uma casa pequena que os ambientes são muito próximos. Então se não tivesse tido essa descrição, talvez eu tivesse imaginado de outra forma.

\subsubsection{Descrição das ações}

O total de inserções referente às ações foi de duzentas e nove. Muitas das inserções utilizadas para as ações foram também de ambientação e descrição de personagens, como podem ser vistos nos Quadros 2 a 7. Apesar desse grande número, a tarefa não foi muito complexa, por causa da presença de poucos diálogos, o que resultou em muitos espaços para as inserções. Somente a abertura do filme tornou-se um pouco complicada.

Depois dos créditos, o filme começa com a câmera dentro de um carro percorrendo uma estrada. A cena dura quase três minutos (2min43s) sem cortes. Ouve-se apenas o barulho do motor do carro. Pensamos em deixar sem AD, mas nosso consultor nos chamou a atenção para o fato de que não era possível o filme ficar sem AD por tanto tempo, sob pena de a pessoa com deficiência visual achar que houve algum problema com o filme. Vale lembrar que a $\mathrm{AD}$ é uma forma de mediação que conjuga de forma importante a acessibilidade com a tradução audiovisual. O Quadro 8 mostra essas inserções: 
Quadro 8: AD da cena inicial de $O$ Grão

\begin{tabular}{|c|c|c|}
\hline 7 & $\begin{array}{l}00: 00: 48,613--> \\
00: 00: 53,651\end{array}$ & $\begin{array}{l}\text { Uma rodovia de mão dupla vista de dentro de um veículo em } \\
\text { movimento corta o sertão. }\end{array}$ \\
\hline 8 & $\begin{array}{l}00: 00: 54,826--> \\
00: 00: 57,948\end{array}$ & Às margens da rodovia uma vegetação seca. \\
\hline 9 & $\begin{array}{l}00: 01: 03,204--> \\
00: 01: 07,241\end{array}$ & À esquerda do vídeo, uma caminhonete branca cruza o veículo. \\
\hline 10 & $\begin{array}{l}00: 01: 09,392--> \\
00: 01: 12,505\end{array}$ & Uma carroça à direita do veículo segue pelo acostamento. \\
\hline 11 & $\begin{array}{l}00: 01: 12,550--> \\
00: 01: 14,843\end{array}$ & Uma moto de farol aceso cruza o veículo \\
\hline 12 & $\begin{array}{l}00: 01: 14,844--> \\
00: 01: 19,875\end{array}$ & $\begin{array}{l}\text { Um carro preto está no acostamento atrás de uma placa de } \\
\text { sinalização. }\end{array}$ \\
\hline 13 & $\begin{array}{l}00: 01: 55,504-> \\
00: 01: 58,745\end{array}$ & Suave curva à direita. \\
\hline 14 & $\begin{array}{l}00: 02: 17,715-> \\
00: 02: 20,448\end{array}$ & Aclive suave. \\
\hline 15 & $\begin{array}{l}00: 02: 26,474--> \\
00: 02: 29,568\end{array}$ & Declive. Ao fundo e à direita do vídeo há um rio. \\
\hline 16 & $\begin{array}{l}00: 02: 31,580--> \\
00: 02: 36,584\end{array}$ & $\begin{array}{l}\text { Linha nylon mergulhada na água. Nela há reflexos da luz do sol } \\
\text { e da vegetação. }\end{array}$ \\
\hline
\end{tabular}

Por ser a cena inicial, essa abertura tem muita importância para o entendimento do filme, porque sabemos no final que o carro é, na verdade, a ambulância que vai buscar o corpo da avó de Zeca, Perpétua. Como a imagem parece não mudar, tivemos que assistir várias vezes até chegar a uma descrição eficiente dessa abertura.

\section{A PESQUISA DE RECEPÇÃO}

Cada um dos protocolos (filmagens, relato retrospectivo e questionário póscoleta) teve o intuito de comprovar ou refutar as seguintes hipóteses: Hipótese 1: Não haveria diferença de recepção entre os dois grupos analisados, tanto os participantes com deficiência visual total e congênita e com baixa visão, entenderiam e apreciariam O Grão, apesar de ser um filme com poucas falas, diálogos e efeitos sonoros; Hipótese 2: Os participantes com deficiência visual total e congênita e com baixa visão conseguiram acompanhar a caracterização dos personagens; Hipótese 3: Os participantes com deficiência visual total e congênita e com baixa 
visão conseguiriam acompanhar a descrição do ambiente. Os participantes dos dois grupos (formado pelos participantes com deficiência visual total e congênita e pelos com baixa visão) serão chamados de P1, P2, P3 e P4 .

No que diz respeito à hipótese 1 , as filmagens com a gravação das reações dos participantes comprovaram essa hipótese. Os participantes sorriram, demonstraram surpresa, compadeceram-se da situação de Zeca e de sua avó e fizeram comentários enquanto assistiam ao filme. Como exemplo de uma dessas reações, podemos citar o comportamento de P1. O participante demonstrou interesse no enredo e esteve bastante atento durante a exibição, captando detalhes revelados pela AD. No momento em que o pai de Zeca amarra um bode em uma árvore, P1 se surpreende. Em outras duas passagens do filme, quando a irmã de Zeca coloca os talheres na mesa e volta para a cozinha dançando e quando o pai reclama da pressa de Fátima em se casar, P1 sorri. Mais adiante, P1 se surpreende ao saber que Zeca adormece enquanto ouve a história contada pela avó.

Os relatos de P1, P2, P3 e P4 também corroboram os resultados das reações. No seu relato retrospectivo, $\mathrm{P} 1$ revelou que mostrar a realidade no campo foi o que mais lhe chamou a atenção no filme e, conhecendo o estilo de vida das pessoas que moram na zona rural da Região Nordeste, afirmou que o filme conseguiu passar essa informação. Disse ainda que os personagens de que mais gostou foram a avó e o Zeca. Sobre a relação entre a história contada pela avó e a história da família, P1 demonstrou ter alcançado claramente a ligação entre as duas, quando citou: "...Ela [avó] passou o filme inteiro sabendo que ela tava doente já, que não ia durar muito tempo, que o neto era bem apegado a ela e que ela tava tentando preparar ele" [sic]. E P1 resumiu o final como sendo "...uma [avó] se foi e uma [a neta Fátima] outra está começando, tá se preparando", o que faz referência ao ciclo da vida mostrado no filme.

O questionário pós-coleta, o qual examinou a opinião dos participantes com deficiência visual sobre os parâmetros, também demonstrou que eles apreciaram o filme, uma vez que fizeram comentários sobre os personagens e o ambiente em que se passa a história. Para P1 a AD estava ótima, sem excesso ou carência de informação e com uma linguagem acessível. Contudo, disse ter ficado com uma pequena dúvida na passagem em que Zeca estava cortando uma folha, pois não soube imediatamente se era uma folha de papel ou de algum vegetal. Sobre a velocidade da $\mathrm{AD}$, achou que estava boa e que o ajudou a compreender o filme. Disse ainda que se tivesse assistido ao filme sem AD, teria entendido a história, porém muitas coisas iriam lhe passar despercebidas, principalmente, porque o filme é bem mais visual e, portanto, tem poucos diálogos. Em sua opinião, o filme se tornou muito mais rico com $\mathrm{AD}$. 
Como as outras duas hipóteses já foram parcialmente abordadas, elas não serão tratadas separadamente como foi o caso da primeira. Como vimos na seção anterior, a hipótese de que não há diferença de recepção da $\mathrm{AD}$ do filme $\mathrm{O}$ Grão por parte dos dois grupos participantes foi testada e os resultados sugerem que os participantes da pesquisa desfrutaram da produção e reagiram de forma semelhante em várias passagens do filme, principalmente, quando a $\mathrm{AD}$ se encarregou de trazer à tona a narrativa visual para os participantes.

$\mathrm{Na}$ cena em que Fátima põe a mesa do jantar e volta para a cozinha da casa da família dançando ao som do seu walkman, por exemplo, os participantes sorriram, pois só a personagem podia ouvir a música através dos fones de ouvido, ou seja, a cena só poderia despertar tal reação das pessoas com deficiência visual a partir da AD. Outro exemplo que confirma esta hipótese é a descrição da passagem em que Zeca furta uma maçã de uma banca de frutas na feira para dar a avó em segredo no quarto, todos também sorriram ao tomarem conhecimento desta informação. Esta reação dos participantes só foi possível a partir das descrições, pois a informação não estava contida nos diálogos do filme. Em não havendo a $A D$, certamente o roubo da maçã não seria notado.

Várias sugestões foram feitas pelos participantes para os roteiros de AD. P2 sugeriu que fossem usadas palavras menos formais, como o uso de aclive e declive, utilizadas no início do filme. Outra sugestão foi a respeito do sincronismo entre a descrição e a ação correspondente no filme, como foi o caso revelado por P3 numa determinada passagem, quando se descreveu que o pai desliga a TV e ainda se pode ouvi-la funcionando por alguns instantes depois de esta informação ter sido veiculada. Esta observação é bastante relevante, pois era pressuposição nossa de que o sincronismo entre a inserção da $\mathrm{AD}$ e a cena audiodescrita poderiam em alguns momentos não ser relevantes para a compreensão do filme. Pelo visto, essa pressuposição não se confirmou.

Sobre a segunda e a terceira hipóteses, o questionário pós-coleta revelou que todos os participantes conseguiram acompanhar a caracterização dos personagens e a descrição do ambiente. Além de melhorar a compreensão do filme, os participantes responderam unânimes que a $\mathrm{AD}$ dos ambientes, do tempo em que se passam as cenas e das características dos personagens do filme são relevantes. Os resultados indicam, então, que a $\mathrm{AD}$ do filme $\mathrm{O}$ Grão, elaborada com base nos parâmetros preconizados por Jimenez-Hurtado (2007), que compreendem a descrição da caracterização dos personagens, ambientação espacial e temporal e as ações, foi eficiente para os quatro participantes da pesquisa. Vimos que P1, P2, P3 e P4 conseguiram alcançar um nível satisfatório de compreensão da narrativa e 
percepção dos elementos visuais da obra, independentemente do grau de acuidade visual de cada um.

Apesar de a pesquisa não ter alcançado resultados conclusivos em virtude do número reduzido de participantes, ela sinalizou que um filme considerado difícil para a maioria dos espectadores pode ser apreciado por uma audiência com deficiência visual a partir da AD. Contudo, pesquisas futuras que contenham um corpus maior poderão confirmar esses resultados.

\section{CONSIDERAÇÕES FINAIS}

A análise do processo de $\mathrm{AD}$ de $\mathrm{O}$ Grão revelou que as inserções mais relevantes do roteiro de $\mathrm{AD}$ foram relacionadas à ambientação e à descrição dos personagens. Isto se deve ao fato de Petrus Cariry construir nesse filme muitos planos com a câmera fixa, cuja narrativa cadenciada propõe uma percepção das relações dos personagens como sertão, bem como sua luta pela sobrevivência nesse ambiente hostil. A economia de elementos acústicos na maioria das cenas reflete diretamente nas ações de introspecção de cada personagem, que compartilha seu universo particular através apenas do olhar. Sem a AD, as informações mais importantes contidas nessas relações ficariam fora de alcance da audiência com deficiência visual.

A pesquisa exploratória apontou para uma boa recepção do filme por parte de deficientes visuais com cegueira congênita e com baixa visão, confirmando ser possível para ambos acessarem, desfrutarem e, principalmente, compreenderem filmes do mesmo gênero de O Grão. O filme é considerado difícil para a maioria dos espectadores, pois foge à narrativa clássica do cinema de Hollywood. Assim sendo, os dados coletados sugeriram que o cinema de autor pode ser apreciado por uma audiência com deficiência visual por meio da AD.

Embora a realização deste trabalho tenha contribuído para a discussão da acessibilidade aos meios audiovisuais por meio de pessoas com deficiência visual, a matéria não se esgota. Desejamos que as pesquisas em desenvolvimento avancem e que novos estudos possam surgir no circuito da $A D$, levando em conta as reais necessidades das pessoas com deficiência visual, ampliando as possibilidades de parâmetros que favoreçam e atendam à demanda reprimida de produtos acessíveis e/ou adaptados a esse público consumidor.

Propomos que futuras investigações ampliem o escopo do estudo a fim de que tenhamos resultados conclusivos. Ademais, cada avanço neste tema irá representar 
um passo essencial na construção de uma sociedade mais justa e igualitária, em que o respeito às diferenças fará toda a diferença.

\section{REFERÊNCIAS BIBLIOGRÁFICAS}

BENECKE, B. Audio-Description. GAMBIER, I. (org) Meta, vol. 49, nº 1, 2004, p. 78-80.

CASADO, A. B. Directores em la sombra: personajes y su caracterización em el guión audiodescrito de "Todo sobre mi madre". Jimenez Hurtado, C. In: Traducción y acessibilidad. Subtitulación para sordos y audiodescripción para ciegos: nuevas modalidades de traducción audiovisual. Frankfurt:Peter Lang, 2007, p. 133-152.

FRANCO, E. P. C. Em busca de um modelo de acessibilidade audiovisual para cegos no Brasil: um projeto piloto. TRADTERM, v. 13, 2007, p. 171-185.

HOLLAND, A. 2009. Audio description in the theatre and the visual arts: images into words. In: Anderman, G. \& Díaz-Cintas, J. Eds. Audiovisual translation: language transfer on screen. Basingstoke; New York: Palgrave MacMillan, p. 170-185.

JAKOBSON, R. Linguística e comunicação. São Paulo: Cultrix, 1995.

JIMENEZ HURTADO C. Una gramática local del guión audiodescrito. Desde la semántica a la pragmática de nuevo tipo de traducción. In: HURTADO, C. J. Traducción y accessibilidad: subtitulación para sordos y audiodescripción para ciegos: nuevas modalidades de traducción audiovisual. Amsterdã: Peter Lang, 2007, p. 55-80.

JIMENEZ HURTADO, C.; RODRÍGUEZ, A.; SEIBEL,C. Un corpus del cine. Teora y practica de la audiodescriptión. Granada: Tragacanto, 2010.

MAGALHÃES, C.; ARAÚJO, V.L.S. Metodologia para elaboração de audiodescrições para museus baseada na semiótica social e multimodalidade: introdução teórica e prática. Revista ALED, no prelo.

MATAMALA, A. La audiodescripción en directo. In: HURTADO, C. J. (ed.). Traducción $y$ accesibilidad. Subtitulación para sordos y audiodescripción para ciegos: nuevas modalidades de Traducción Audiovisual. Frankfurt AM Main: Peter Lang, 2007, p. 121-132.

OLIVEIRA JÚNIOR, J.N. Ouvindo imagens: a audiodescrição de obras de Aldemir Martins. Dissertação de Mestrado não publicada. Programa de Pós-Graduação em Linguística Aplicada, Universidade Estadual do Ceará, Fortaleza, 2011.

PAYÁ, M. P. La audiodescrípción: traduciendo el lenguaje de las cámaras. In: HURTADO, C. J. (ed.).Traducción y accesibilidad. Subtitulación para sordos y audiodescripción para ciegos: nuevas modalidades de Traducción Audiovisual. Frankfurt AM Main: Peter Lang, 2007, p. 81-92.

SILVA, M. C. C. C. da. Com os olhos do coração: estudo acerca da audiodescrição de

desenbos animados para o público infantil. Dissertação de Mestrado não publicada. Programa de Pós-Graduação em Letras e Linguística, Universidade Federal da Bahia, Salvador, 2009. 
SNYDER, J. The visual made verbal across arts discipplines - across the globe. Translating Today Magazine. Volume 4, Julho de 2005.

VANOYE, F., GOLIOT-LÉTÉ, A. Ensaio sobre a análise fílmica. Campinas: Papirus, 1994.

Recebido: 02/09/2011

Aceito: 30/10/2011 